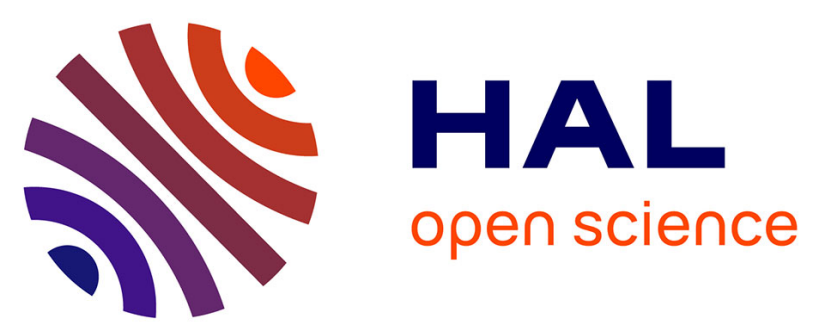

\title{
Diazene-Functionalized Lamellar Materials as Nanobuilding Blocks: Application as Light-Sensitive Fillers to Initiate Radical Photopolymerizations
}

Cyrielle Dol, François Vibert, Michèle P. Bertrand, Jacques Lalevée, Stéphane Gastaldi, Eric Besson

\section{To cite this version:}

Cyrielle Dol, François Vibert, Michèle P. Bertrand, Jacques Lalevée, Stéphane Gastaldi, et al.. Diazene-Functionalized Lamellar Materials as Nanobuilding Blocks: Application as Light-Sensitive Fillers to Initiate Radical Photopolymerizations. ACS Macro Letters, 2017, 6 (2), pp.117 - 120. 10.1021/acsmacrolett.6b00949 . hal-01491849

\author{
HAL Id: hal-01491849 \\ https://hal.science/hal-01491849
}

Submitted on 3 May 2018

HAL is a multi-disciplinary open access archive for the deposit and dissemination of scientific research documents, whether they are published or not. The documents may come from teaching and research institutions in France or abroad, or from public or private research centers.
L'archive ouverte pluridisciplinaire HAL, est destinée au dépôt et à la diffusion de documents scientifiques de niveau recherche, publiés ou non, émanant des établissements d'enseignement et de recherche français ou étrangers, des laboratoires publics ou privés. 


\title{
Diazene-Functionalized Lamellar Materials as Nanobuilding Blocks: Application as Light Sensitive Fillers to Initiate Radi- cal PhotoPolymerizations
}

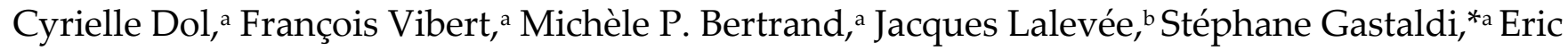 \\ Besson $^{* a}$
}

aAix Marseille Univ, CNRS, ICR, Marseille, France.

bInstitut de Science des Matériaux de Mulhouse IS2M - UMR CNRS 7361 - UHA, 15, rue Jean Starcky, 68057

Mulhouse Cedex, France

\begin{abstract}
New polysilsesquioxane-based lamellar materials, functionalized with radical precursors, were synthesized. They play a double role in the preparation of composite materials: first, as filler homogenously dispersed in the monomer after delamination, second as radical initiator in photopolymerization. These polysilsesquioxanes enable fast and efficient photopolymerization upon UV light for thick samples. High conversions in monomers as well as the formation of hybrid polymers covalently linked to the filler are observed. This strategy, based on a double bottom-up approach, avoids the solubility/dispersion problem encountered in the classical preparation of composite polymers from pre-formed organic polymers.
\end{abstract}

The design of new functional hybrid materials is not only a challenge for fundamental synthetic chemistry but it also opens up ways to innovative industrial applications. ${ }^{1}$ These composite materials combine the properties of an organic phase and an inorganic phase. If one of the phases has at least one dimension lower than 100 $\mathrm{nm}$, the materials are referred to as nanocomposites. The main difficulty lies in the homogeneous dispersion of these nano-objects in the host matrix. Ideally, once spread in the composite, the large surface of the nanofillers strengthens the matrix-reinforcement interface and induces effects on the macroscopic properties, structural or functional, of the nanocomposite. ${ }^{2}$ Different strategies can be used to access to complex multifunctional nanocomposites, either from molecular precursors or from well-defined nano-objects as starting materials. As a result, it is possible to synergistically combine the properties of the organic and inorganic components. The first route relies on the bottom-up approach and the synthesis of the materials is achieved through soft chemical processes (sol-gel process, MOF synthesis, hydrothermal synthesis) from well-designed precursors. The second pathway implies the use of pre-formed nano-objects (nanoparticles, nano sheets, polymers...) as starting nanobuilding blocks, their transformation leads to hybrid materials. Usually nano-objects used are composed of an inorganic network that can be: clays, layered double hydroxides (LDH), silicates, metal oxides, metal phosphates or metal chalcogenide. Two hybridization strategies can be used: (i) intercalation / delamination of a lamellar material already formed or (ii) one-pot synthesis from a mixture of inorganic and organic precursors. ${ }^{3,4}$

We have shown that the lifetimes of arylsulfanyl radicals anchored in the framework ${ }^{5}$ or on the pore ${ }^{6}$ of mesoporous silicas could dramatically improve depending on the structure of the hybrid material.

Although important in both cases, the effect of the silica structure on the radical lifetime turned out to be more important when the radical precursors were located in the pores of silicas rather than in the walls. The formation of an organic monolayer on the pore surface disfavoured the formation of disulfides, which is the main contributor to the decay of the EPR signal in this case. ${ }^{6}$ In these materials, the arylsulfanyl half-lifetime ( $\left.\mathrm{t}_{1 / 2}\right)$ reaches values superior to 60 hours i.e., an incredible improvement with respect to the value of $200 \mu$ s estimated by flash photolysis for the phenylsulfanyl radical in solution. ${ }^{7}$ For the sake of comparison, we have explored the radical behaviour in lamellar functional materials, namely polysilsesquioxanes.

Beyond the fundamental interest of the properties of confined radicals, lamellar polysilsesquioxanes are po- 
tential nanobuilding blocks for the design of hybrid materials. A strategy similar to that reported by Blumstein for the polymerization of monomers inserted between sheets of clays could be applied. ${ }^{8}$ Considering the overall process, these new lamellar materials would enable to associate the two synthetic routes of hybrid materials described above: by synthesizing first hybrid lamellar polysilsesquioxanes by sol-gel process, and then by using the resulting nano-sheets as both nanobuilding blocks and polymerization initiators after delamination by insertion of monomer between the sheets.

Lamellar materials, LAM-1 and LAM-2, were prepared from bis(triethoxysilyl) precursors $\mathbf{1}^{5}$ and $2^{9}$ via the solgel process (Scheme 1). ${ }^{10}$ These precursors were designed to generate sulfur- or oxygen-centered radicals thanks to a double fragmentation triggered by photolysis. 5,9 They differ by the nature of the spacer between the aromatic ring and the silicon atom, i.e. ether or urea.

These materials were tested as radical polymerization photoinitiators, owing to their potential ability to generate free radicals upon light exposure. In this context, the use of LAM-1 and LAM-2 would achieve a real breakthrough due to their dual behavior as they are both fillers and photoinitiators. Moreover, this approach would enable to covalently link the polymer to the filler. Albeit, the use of fillers to improve the mechanical properties of polymers is currently very broad, their presence in photopolymerization is usually a drawback as they can diffuse the light and consequently reduce the penetration of light into thick samples. ${ }^{11}$

In the present paper, LAM-1 and LAM-2 were evaluated as light sensitive fillers to initiate the polymerization of thick samples.

\section{Scheme 1. Synthesis of LAM-1 and LAM-2}
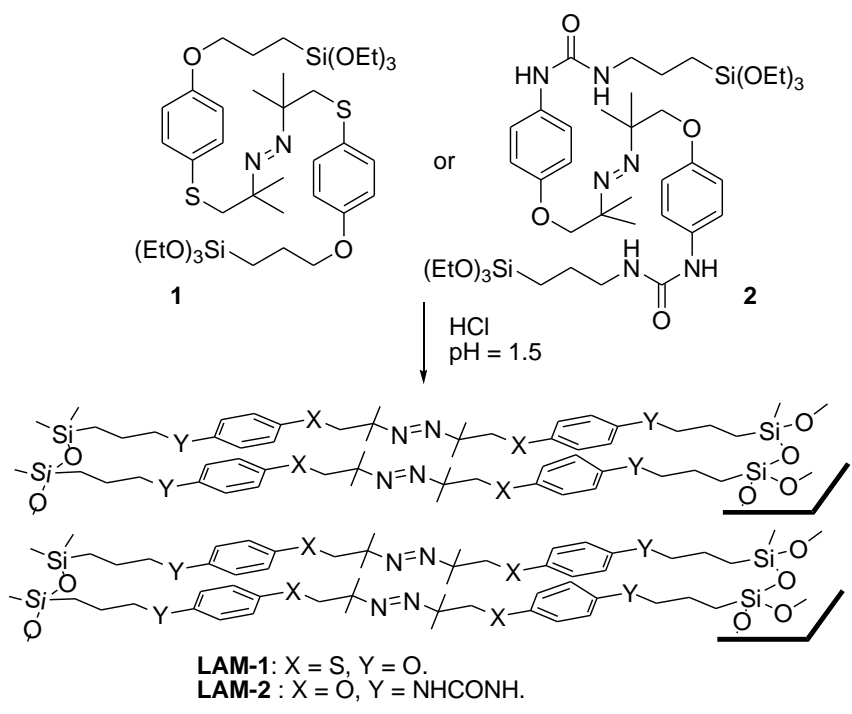

The X-ray powder diffraction (XRD) diagrams of LAM-1 and LAM-2 display the characteristic peaks assigned to lamellar structures. ${ }^{12}$ LAM-1 exhibits first and second order peaks at $q=8.29 \mathrm{~nm}^{-1}$ and $17.90 \mathrm{~nm}^{-1}$ which are characteristic of a lamellar structure with $0.35 \mathrm{~nm}$ intersheet distance $(d=2 \pi / q)$ (Figure 2). The broad peak at $q=$ $1.90 \mathrm{~nm}^{-1}$ corresponds to an interlayer distance of $3.3 \mathrm{~nm}$. The sharp peak at $q=7.68 \mathrm{~nm}^{-1}\left(\mathrm{~d}=0.87 \mathrm{~nm}^{-1}\right)$ could fit with the distance between two sulfur atoms in the precursor. LAM-2 shows a characteristic broad peak at $q$ $=1.90 \mathrm{~nm}^{-1}$ which is consistent with an interlayer distance of $3.3 \mathrm{~nm}$. The broad peak at $q=18.09 \mathrm{~nm}^{-1}$ corresponds to an intersheet distance of $0.35 \mathrm{~nm}$. An interchain distance of $0.43 \mathrm{~nm}$ is evidenced by the peak at $q=15.1 \mathrm{~nm}$ ${ }^{1}$. The XRD highlights the incidence of the ureido moieties on the lamella structure, sharp peaks can be assigned to the distance between two carbonyl groups $(q=$ $\left.13.3 \mathrm{~nm}^{-1}, 0.47 \mathrm{~nm}\right)$ and to the $\mathrm{N} \cdots \mathrm{O}$ distance $(q=10.1$ and $20.2 \mathrm{~nm}^{-1}, 0.31$ and $\left.0.62 \mathrm{~nm}\right) .{ }^{13}$ The comparison between the XRD analysis of LAM-1 and LAM-2 clearly shows a higher inter-lamella organization for LAM-1 whereas the presence of the urea in LAM-2 increases the organization inside the sheet.

The properties of the arylsulfanyl and phenoxyl radicals generated from the photolysis of these precursors was investigated by EPR. In a typical procedure, the functionalized material was degassed $\left(10^{-5} \mathrm{mbar}\right)$ in a $4 \mathrm{~mm}$ quartz-glass tube and heteroatom-centered radicals were generated via the light-induced decomposition of the diazene ${ }^{5,9}$ inside the spectrometer cavity (xenon lamp (200-800 nm) fitted with a $360 \pm 10 \mathrm{~nm}$ filter).

At room temperature and under irradiation, LAM-1 led to an anisotropic signal assigned to the corresponding arylsulfanyl radical. The EPR parameters of these signals (Table 1) were in agreement with the formation of arylsulfanyl radicals ${ }^{5,6,14}$ for which the $g$ tensor is axisymmetrical and the spin density is localized on the sulfur atom..$^{15}$ The thermal decomposition of the diazene moieties at $473 \mathrm{~K}$ enabled the observation of an isotropic signal with a $2.009 \mathrm{~g}$-factor. The half-lifetimes of the arylsulfanyl radicals were measured graphically by monitoring the decay of the signal of highest intensity. They were in the same order of magnitude as those registered for radicals generated from symmetrical diazene precursors located in the wall of the silica, i.e. $2.3 \mathrm{~h}$ at $273 \mathrm{~K}$ and $3 \mathrm{~min}$ at $473 \mathrm{~K} \cdot{ }^{5}$ Concerning LAM-2, the EPR study performed at $293 \mathrm{~K}$ under irradiation showed the formation of an isotropic signal with a $2.004 \mathrm{~g}$ factor, which is consistent with a phenoxyl radical. ${ }^{16}$ Amazingly, the half-life time of the phenoxyl radical in this lamellar organization was higher than 2 years. In this system, this radical can be considered as stable ${ }^{17}$ since the EPR tube cannot be considered airtight over such a long peri- 
od. This result confirms that changing neither the electronic properties nor the steric hindrance of the phenoxyl radical, it is possible to increase the lifetime of a transient radical by controlling its close surroundings.

Table 1. Half-lifetime of the arylsulfanyl and phenoxyl radicals generated from LAM-1 and LAM-2

\begin{tabular}{|l|l|l|l|l|l|l|}
\hline & & Conditions & $\mathrm{g}_{/ /}$ & $\mathrm{g}_{\perp}$ & $\mathrm{g}_{\text {iso }^{\mathrm{a}}}$ & $\mathrm{t}_{1 / 2} \mathrm{~b}^{\mathrm{b}}$ \\
\hline $\mathrm{a}$ & $\begin{array}{l}\text { LAM- } \\
\mathbf{1}\end{array}$ & $\mathrm{h}^{\mathrm{c}}$ & 2,014 & 2,008 & 2,010 & $2.3 \mathrm{~h}$ \\
\hline $\mathrm{b}$ & $\begin{array}{l}\text { LAM- } \\
\mathbf{1}\end{array}$ & $473 \mathrm{~K}^{\mathrm{d}}$ & - & - & $2,009 \mathrm{e}$ & $3 \mathrm{~min}$ \\
\hline $\mathrm{c}$ & $\begin{array}{l}\text { LAM- } \\
\mathbf{2}\end{array}$ & $\mathrm{h}^{\mathrm{f}}$ & - & - & $2,004^{\mathrm{e}}$ & $\begin{array}{l}> \\
\text { years }\end{array}$ \\
\hline
\end{tabular}

${ }^{\mathrm{a}} g_{\text {iso }}=\left(2 g_{\perp}+g_{/ /}\right) / 3$ from graphically determinated $g_{\perp}$ and $g / / .{ }^{18} \mathrm{~b}$ Determined from the double integrated EPR signal at 293 K. c Xenon lamp (200-800 nm). d Without irradiation. e Isotropic signal. ${ }^{\mathrm{f}}$ Xenon lamp (200-800 nm) fitted with a 360 $\pm 10 \mathrm{~nm}$ filter.

The observed lifetime difference between the sulfanyl and phenoxyl radicals could be related to the spin density at the heteroatom $(85 \%$ at the sulfur atom in the case of arylsulfanyl radicals ${ }^{6}$ versus $27 \%$ at the oxygen atom in the case of phenoxyl radical ${ }^{19}$ ) and to the mobility of the organic chains in the lamella. The increase of the half-life time of the sulfur-centered radical up to $2.3 \mathrm{~h}$ shows that the formation of the disulfide, main cause of the signal decay, is slowed down with respect to phenylsulfanyl radical in solution. The evolution of the phenoxyl radical is different since the spin density is delocalized on the ortho and para positions of the aromatic ring, which leads the signal to decay through the formation of $\mathrm{O}-\mathrm{C}$ and $\mathrm{C}-\mathrm{C}$ coupling products. ${ }^{20}$ These reactions are disfavored in the lamella because of the low mobility resulting from strong associations, evidenced by the XRD and by IR analyses which show the presence of associated urea carbonyl moieties $\left(v_{\mathrm{c}=0}=1635\right.$ $\left.\mathrm{cm}^{-1}\right)$.

\section{Scheme 2. Photopolymerization process}

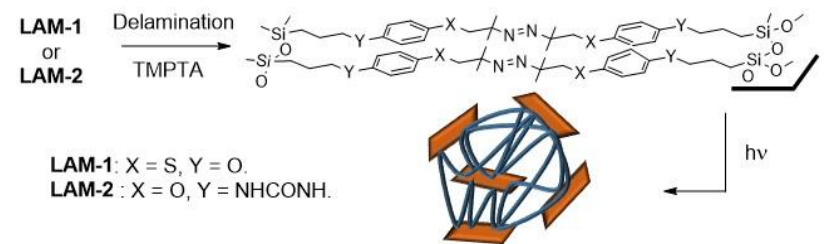

These lamellar materials were tested as photoinitiators for radical polymerization (Scheme 2). As regard to trimethylolpropane triacrylate (TMPTA), the photopolymerization process did not occur without any photoinitiator (Figure 1- curve 3). Interestingly, in presence of LAM-1 or LAM-2, a clean and efficient photopolymerization reaction was observed. The NIR absorption peaks representative of the acrylate $C=C$ double bond are found at three different wavenumbers: $\sim 4490 \mathrm{~cm}^{-1} ; 4736 \mathrm{~cm}^{-1}$ or $6165 \mathrm{~cm}^{-1}$; a clear consumption of the acrylate functions upon irradiation in presence of LAM-1 or LAM-2 was registered as evidenced by the strong decrease of their intensity in Figure 1B. An inhibition period of $\sim 30 \mathrm{~s}$ was noted in presence of LAM-2 but the polymerization started almost immediately in presence of LAM-1. This is also in agreement with the higher conversion of the acrylate monomer for LAM-1 ( $80 \%$; Figure 1 - curve 1) compared to LAM-2 (Figure 1 - curve 2). These data unambiguously show that LAM-1 and LAM-2 can be considered as radical photoinitiators for the polymerization of acrylates but also that LAM-1 is more efficient than LAM-2. It must be underlined that the polymerization was initiated by the addition of a heteroatom- or a carbon-centered radical onto the acrylate double bond. The inhibition phenomenon might be related to the relative rates of fragmentation of $\beta$-sulfur or $\beta$-oxygen carbon-centered radicals. The fragmentation of the former is fast; it generates sulfur-centered radicals highly efficient to initiate the polymerization by adding to the monomers. ${ }^{21}$ The variation of $\log \mathrm{k}_{\mathrm{a}}$ for the addition of $p$-substituted arylsulfanyl radical ranges between 5.7 and 6.7 highlighting the weak incidence of the substituent. ${ }^{22}$ With LAM-2, in all likelihood the polymerization starts with the addition of a carbon centered radical rather than a phenoxy radical. Due to the slower fragmentation, ${ }^{9}$ part of the tertiary carbon centered-radicals reacts with residual oxygen before the initiation occurs. In other words, the absence of inhibition for LAM-1 evidences its efficiency as initiator in the presence of air.

In all cases, the filler, i.e. the radical precursor sheet, is covalently linked to the polymer. The polymerization of thick samples (up to $1.4 \mathrm{~mm}$ ) was fully possible ( $70 \%$ of acrylate function conversion in less than $100 \mathrm{~s}-$ Figure $1)$. 

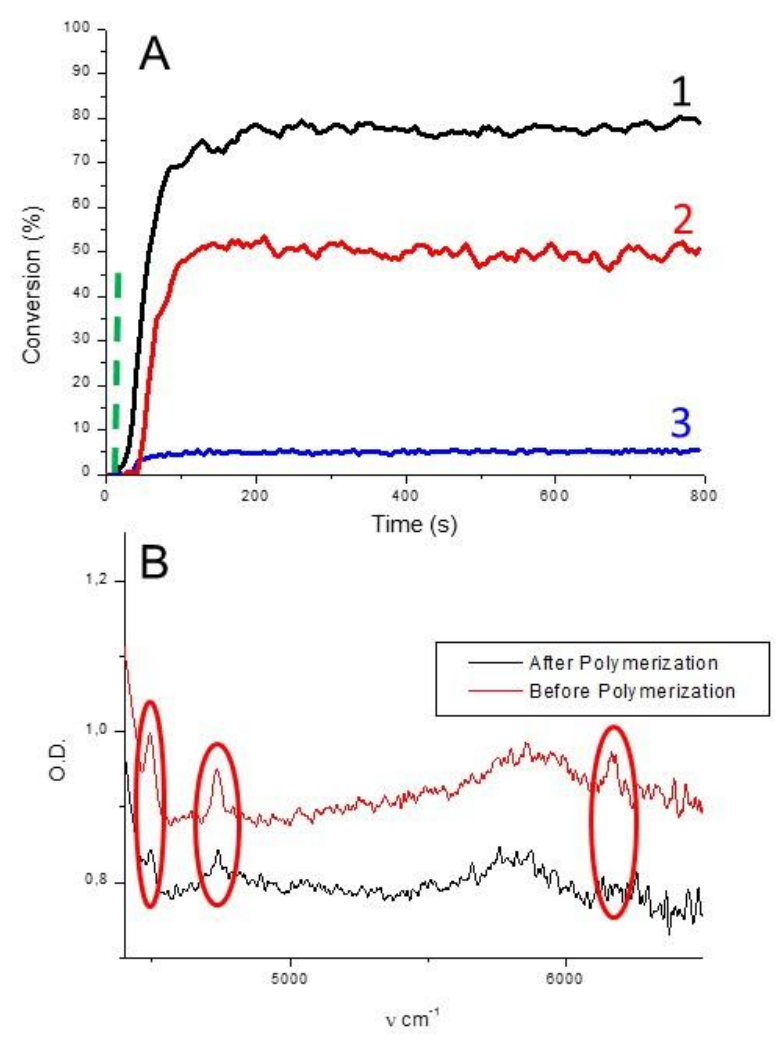

Figure 1. (A) Photopolymerization profiles of TMPTA under air (acrylate function conversion vs. irradiation time) in the presence of LAM-1 (1) (10\% w/w); LAM-2 (2) $(10 \%$ $\mathrm{w} / \mathrm{w}$ ) or without photoinitiator (3); the irradiation starts for $t=10 \mathrm{~s}$; (B) NIR-FTIR spectra before and after polymerization of TMPTA in presence of LAM-1

Evidence for a homogeneous dispersion of the nanobuilding block in the monomer phase was provided by WAXS analysis performed on the mixture monomer/LAM-1. The comparison with the WAXS profile of LAM-1 showed clearly the disappearance of the characteristic peaks of a lamellar organization (Figure 2), in other words a delamination occurred during the preparation of the sample leading to a homogeneous mixture of sheet in the monomer. However, it must be underlined that a broad signal $\left(q=1.90 \mathrm{~nm}^{-1}\right)$ was still present after delamination which show the stability of the sheets in the presence of monomer. TEM analysis were then performed, they gave no evidence for the formation of aggregates but no additional information could be drawn because of the low contrast due to the high organic content.

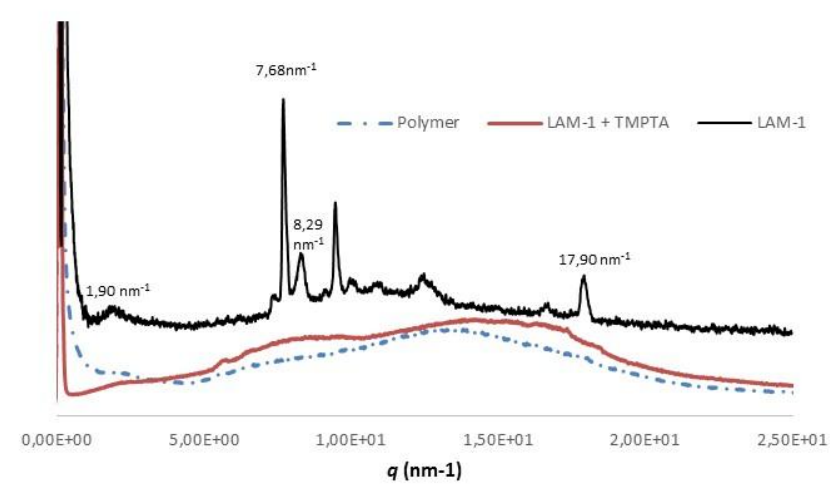

Figure 2. WAXS profiles (grey : LAM-1, orange : LAM-1 + TMPTA, blue : polymer)

To conclude, lamellar hybrid materials functionalized with radical precursors were designed for the generation of oxygen- or sulfur-centered radicals by photolysis or thermolysis. The amazing half-lifetimes recorded by EPR for these radicals are consistent with the high structuration of the materials through self-assembly. These nanoobjects, i.e., the sheets, were used as nanobuilding blocks and as initiators for photopolymerization under air. The polymerization was more efficient with the sulfur containing filler than with the oxygenated one. High conversions in hybrid polymers covalently linked to the filler were observed. The major advantage of the method is to avoid the solubility/dispersion problem encountered in the classical preparation of composite polymers from pre-formed organic polymers, ${ }^{23}$ thanks to a double bottom-up approach, the first for the nano-object and the second for the polymerization.

\section{ASSOCIATED CONTENT}

Supporting Information: Characterizations for the organic compounds and the derived materials (IR, NMR, WAXS). EPR spectra and decay curves.

\section{AUTHOR INFORMATION}

\section{Corresponding Author}

*E-mail: stephane.gastaldi@univ-amu.fr

*E-mail: eric.besson@univ-amu.fr

\section{Funding Sources}

Any funds used to support the research of the manuscript should be placed here (per journal style).

Notes

The authors declare no competing financial interest.

\section{ACKNOWLEDGMENT}

The authors acknowledge the Agence Nationale de la Recherche for funding (ANR-12-JS07-005).

\section{REFERENCES}


${ }^{1}$ (a) Sanchez, C.; Belleville, P.; Popall, M.; Nicole, L. Chem. Soc. Rev. 2011, 40, 696-753. (b) Hussain, F.; Hojjati, M.; Okamoto, M.; Gorga, R. E. J. Compos. Mater. 2006, 40, 1511-1575.

2 (a) Gerasin, V. A.; Antipov, E. M.; Karbushev, V. V.; Kulichikhin, V. G.; Karpacheva, G. P.; Talroze, R. V.; Kudryavtsev, Y. V. Russ. Chem. Rev. 2013, 82, 303-332. (b) Thostenson, E. T.; Li, C.; Chou, T.-W. Compos. Sci. Technol. 2005, 65, 491-516.

${ }^{3}$ Fernandes, F. M.; Baradari, H.; Sanchez, C. App. Clay Sci. 2014, 100, 2-21.

${ }^{4}$ For a typical example of one-pot synthesis involving photopolymerization and sol-gel process, see: Amerio, E.; Sangermano, M.; Malucelli, G.; Priola, A.; Voit, B. Polymer 2005, 46, 11241-11246.

${ }^{5}$ Vibert, F.; Marque, S. R. A.; Bloch, E.; Queyroy, S.; Bertrand, M. P.; Gastaldi, S.; Besson, E. J. Phys. Chem. C 2015, 119, 54345439.

${ }^{6}$ Vibert, F.; Marque, S. R. A.; Bloch, E.; Queyroy, S.; Bertrand, M. P.; Gastaldi, S.; Besson, E. Chem. Sci. 2014, 5, 4716-4723.

${ }^{7}$ Thyrion, F. C. J. Phys. Chem. 1973, 77, 1478-1482.

${ }^{8}$ Blumstein, A. J. Polym. Sci. Part A 1965, 3, 2653-2664.

${ }^{9}$ Dol, C.; Bertrand, M. P.; Gastaldi, S.; Besson, E. Tetrahedron 2016, 72, 7744-7748.

${ }^{10}$ (a) Mehdi, A.; Reye, C.; Corriu, R. Chem. Soc. Rev. 2011, 40, 563-574. (b) Lofgreen, J. E.; Ozin, G. A. Chem. Soc. Rev. 2014, 43, 911-933.

${ }^{11}$ Fouassier, J.P.; Lalevée, J., Photoinitiators for Polymer Synthesis-Scope, Reactivity, and Efficiency; Wiley-VCH Verlag GmbH \& Co. KGaA: Weinheim, 2012
${ }^{12}$ Besson, E.; Mehdi, A.; Reyé, C.; Gaveau, P.; Corriu, R. J. P. Dalton Trans 2010, 39, 7534-7539.

${ }^{13}$ Shimizu, L. S.; Smith, M. D.; Hughes, A. D.; Shimizu, K. D. Chem. Commun. 2001, 1592-1593.

${ }^{14}$ (a) Walton J. C., Encyclopedia of Radicals in Chemistry, Biology and Materials; Wiley, 2012; p 151-174. (b) Schmidt, U. Angew. Chem., Int. Ed. 1964, 3, 602-608. (c) Rundel, W.; Scheffler, K. Angew. Chem., Int. Ed. 1965, 4, 243-244.

${ }^{15}$ Schmidt, U.; Müller, A. Angew. Chem., Int. Ed. 1963, 2, 216.

16 a) Panagiota, S.; Louloudi, M.; Deligiannakis, Y. Chem. Phys. Lett. 2009, 472, 85-89. b) Kaneko, T.; Iwamura, K.; Nishikawa, R.; Teraguchi, M.; Aoki, T. Polymer 2014, 55, 1097-1102. c) Innami, Y.; Kiebooms, R. H. L.; Koyano, T.; Ichinohe, M.; Ohkawa, S.; Kawabata, K.; Kawamatsu, M.; Matsuishi, K.; Goto, H. J. Mater. Sci. 2011, 46, 6556-6562. C) Awaga, K.; Sugano, T.; Kinoshita, M. Chem. Phys. Lett. 1986, 128,587-590.

${ }^{17}$ (a) Griller, D.; Ingold, K. U. Acc. Chem. Res. 1976, 9, 13-19. (b) Griller, D.; Ingold, K. U. Acc. Chem. Res. 1980, 13, 193-200.

${ }^{18} \mathrm{~g}_{\text {iso }}=\left(2 \mathrm{~g}_{\perp}+\mathrm{g} / /\right) / 3$ see: Gerson, F.; Huber W., Electron Spin Resonance Spectroscopy of Organic Radicals; Wiley-VCH, 2003, pp 97-165.

${ }^{19}$ (a) Stone, T. J.; Waters, A. W. J. Chem. Soc. 1964, 213-218. (b) Fehir, R J.; McCusker, J K.J. Phys. Chem. A, 2009, 113, 9249-9260

${ }^{20}$ (a) Nonhebel, D. C.; Walton, J. C. In Free-radical chemistry; structure and mechanism; Cambridge University Press, 1974; Chap 10, pp 328. (b) Asatryan, R.; Davtyan, A.; Khachatryan, L; Dellinger, B. J. Phys. Chem. A 2005, 109, 11198-11205.

${ }^{21}$ Lalevée, J.; Allonas, X; Fouassier, J. P. J. Org. Chem. 2006, $71,9723-9727$.

${ }^{22}$ Ito, O.; Matsuda, M. Prog. Polymer Sci. 1992, 17, 765-951.

${ }^{23}$ Hong, R.Y.; Chen, Q. Adv. Polym. Sci. 2014, 267, 1-38. 
Table of Contents (TOC)

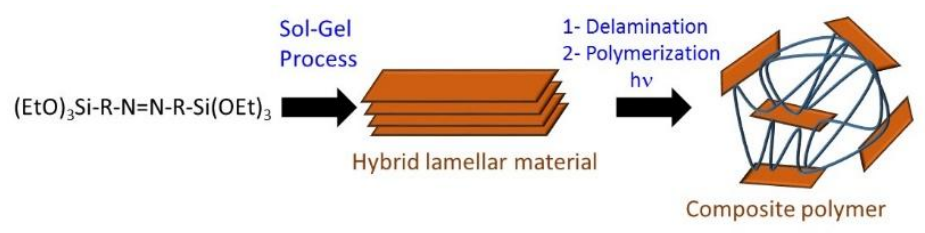

